\title{
Policy support of economic growth corridors: A Canadian approach to urban-rural development
}

\author{
Ron O. Gaudet, Ec.D
}

\begin{abstract}
The purpose of this paper is to provide a rationale for a federal policy to support the development of growth corridors within Canada. The intent is to provide insight into growth corridors by defining what is meant by them, by looking at several North American examples and by providing an in-depth look and rationale of the newly formed Halifax - Moncton Growth Corridor. The paper offers lessons learned from this process which include that all stakeholders should be engaged and regional benefits and opposing interest must be identified. The researcher argues that a policy that addresses growth corridor development would encourage regions to work more collaboratively and would assist the government address the urban - rural dilemma.
\end{abstract}

Keywords: growth corridors, policy, Halifax-Moncton growth corridor

\section{Introduction}

Canada is an extremely large country. It is sparsely populated and its economy is extremely diverse depending on its geography. The country is politically held together by a convoluted Constitution. However, its reality is that it encompasses a territory which is so large that it is really a country of diverse regions; diverse in their economy, their culture, their politics and their ability to integrate themselves economically, culturally and socially.

For this reason, it has always been difficult to implement meaningful federal policy relative to economic development that serves all Canadians well. There is another reality that further compounds the difficult job of federal development policy. That is the fact that that Canada is not only a country of rather diverse regions but that within those regions there is rural - urban split in population. While there is a significant trend towards a furthering of urbanization within Canada as a whole, nearly a quarter of all Canadians still live in a rural setting. This has made it difficult if not impossible, for a 'one size' fits all federal policy.

Depending on the government of the day there tends to be a trade-off of policy directed towards either an urban or rural agenda. This furthers the gap between the two economies, as it assists the agenda most during a crisis and tends to ignore the agenda that is less vocal. The problem with this philosophy is that intervention does not always reap the highest output during crisis. For example, if federal economic policy is primarily focused on supporting a rural agenda, the urban centres tend to get short shrift during their growth cycles and infrastructure suffers. Accordingly, once an urban centre's infrastructure is at a point where it can no longer sustain growth, crisis situations can arise. Then the tendency is for civic leaders to look for federal assistance. When federal policy tends to be too focused on the urban agenda the rural areas suffer; there is less ability for the government to react quickly to seasonal employment issues and sector specific issues such as resource depletion in the fisheries or mining sectors.

Federal policy historically has dealt mostly with the urban- rural reality through crisis management. This unfortunately has tended to deepen the divide over time and leads to a situation where one benefits at the expense of the other. It was this situation which got Enterprise Greater Moncton and the Greater Halifax Partnership thinking in terms of an economic growth corridor (Figure 1).

Figure 1. Halifax-Moncton growth corridor

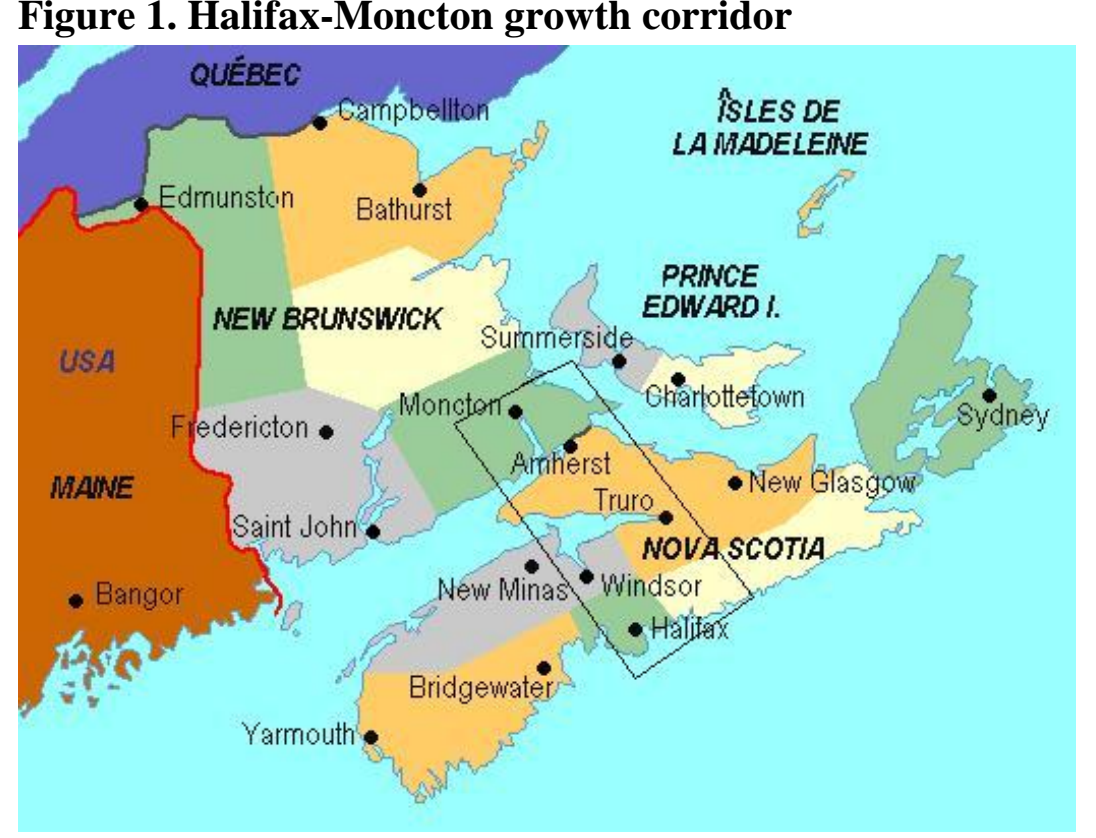

It is our belief that if this corridor was used as a template for other urban - rural areas, and if there was policy in place to assist to with the development of regional growth corridors, that urban and rural Canada would find themselves by virtue of integrated economies and cultures, focused not on competing agendas, but on a consistent agenda of growth, leading to enhanced social and economic wellbeing for all.

\section{Definition of a growth corridor}

The simplest way to explain the concept of an economic corridor is by using the example of a shopping mall. A typical shopping centre is often comprised of a large identifiable anchor store on either end of the centre. Halls (corridors) made up of smaller specialty stores link these anchor stores. The relationship between the anchors and the corridor stores is one of complementing each other's 
strengths. While competition exists amongst the various stores, there is a basic belief that together they bring critical mass and become a destination point for the shopper.

This analogy can be used to explain the growth corridor concept. The corridor would usually link two or more larger urban centres. The route linking the two communities and the smaller communities along that route including the urban centres would make up a corridor. Traditionally the two urban centres would compete with each other for economic activity. The communities along the corridor would similarly compete with each other. The traditional attitude is that any one community's gain economically is a loss for the other communities. However, the corridor concept recognizes that there is interdependence amongst all of the stakeholders in and along the corridor. Dr Brendan Williams, Lecturer in Urban Economics and the Faculty Research Fellow Faculty of the Built Environment, Dublin Institute of Technology states, "adjacent cities can heavily influence the region between them. Typically, most economic development occurs along the main transportation axis linking the urban areas, with each city acting as a pole of growth at either end. This type of development is known as an Economic Corridor" (Williams, 2001,http:/www.dublinpact.ie/ conference details/ ConferenceReview/speakers/Bwilliams/bwilliams3.html).

\section{Creating a growth corridor}

Growth corridors are really about viewing a region from a different perspective. It is about seeing the potential of a region without the confines of jurisdictional issues but in the context of a harmonious or homogeneous approach to growth. Simply put, it is the analogy of "together we are stronger" played out in an economic and social scene.

The Brussels-Antwerp corridor provides a good example of a corridor structure, which was established to unite a region. For years, economic development in the urban centres of Belgium was stressing the surrounding areas and negatively affecting rural economies. There was also a great deal of stress on the infrastructure of the inner cities.

When looking for comparable examples for the development of the Halifax-Moncton Growth Corridor, we reviewed over twenty economic models throughout North America and Europe. Of these we selected five that were considered to be the most similar to our approach.

The following will provide a brief overview of the summary/background, size and scope, structures and activities for the following corridors:

- The Florida High Tech Corridor;

- The Central Texas Economic Corridor;

- Ontario East;

- The Tennessee Valley Corridor;

- The Hartford-Springfield Knowledge Corridor.

\section{The Florida high tech corridor: Summary/background}

The Florida High Tech Corridor was established as a Council in 1996 with a mission to attract, retain and grow high tech industry along Florida's High Tech Corridor. It includes 22 counties.

Founded by:

- University of Central Florida;

- University of South Florida;

- 15 high tech companies;

- Funded by the Florida Legislature and participating technology companies.

Council activities:

- Investment Attraction and Retention: Examples: Agere Systems microelectronics fabrication facility ( $\$ 1.7$ billion investment) and Uniroyal Optoelectronics expansion (77,000-square-foot facility);

- Funding research in the Corridor: $\$ 80$ million worth of projects in past four years;

- Educational initiatives to grow the high tech workforce.

Advocacy:

- Support and advocacy for new state and local incentives;

- Brings together governmental, environmental, regulatory and business leaders in the Corridor communities to work together to identify and facilitate the resolution of issues that must be addressed before successfully attracting new industry;

- Marketing of the Corridor - brochures, trade shows, web, etc.

Examples of the council's work:

- The development of marketing materials for use by the counties and cities within the corridor;

- The establishment of the Tech 4 Consortium which provides instructional materials for enhanced curriculum, faculty development and 'traveling' module labs created to introduce and encourage thousands of students throughout the state to pursue careers in a wide range of technology fields;

- The development of IT competency-based web survey system that matches the skills of workers with the needs of employers and coursework available at local educational institutions;

- Lobbied for tax breaks on manufacturing equipment; 
- Encouraged the state government to develop 'quick response training programs' for new industry.

Some results of the corridor project:

This corridor has seen thousands of new jobs created and billions of dollars in investments in Florida since its beginnings. With over $\$ 80$ million spent in new research, the corridor was named one of the world's top seven intelligent communities in 2002 (ShiftCentral, 2003).

\section{Central Texas economic corridors summary/background}

The Central Texas Economic Corridor (CTEC) was established to provide relocation assistance to companies looking at expanding in Central Texas.

Founded in 2001 by:

- Development Corporation of Belton;

- Copperas Cove Economic Development Corporation;

- Greater Killeen Chamber of Commerce;

- Temple Economic Development Corporation;

- Greater Waco Chamber of Commerce.

Size and scope:

- Central Texas Corridor is located between Austin and Dallas on Interstate 35 and US Highway 190;

- $300 \mathrm{~km}$ long corridor;

- 80 per cent of Texas' population is within 200 miles of the CTEC.

Structure:

- Does not have any full time staff. Efforts are coordinated by the five partner organizations;

- Targeted Industries:

- Military; Healthcare/Medical Services \& Research; Business Services; Manufacturing; Aerospace and Education.

Council activities:

- Exhibiting at trade shows;

- Development of regional marketing materials;

- The maintenance of a Corridor real estate database.

Examples of the council's work:

- Exhibited at PlasticsUSA;

- Exhibited at SEMICON;

- Exhibited at National Plastics Exposition;

- Exhibited at the Medical Design and Manufacturing trade show;

- Exhibiting at PlastTec in 2003.

Some results of the corridor project:

The corridor has led to the creation of a comprehensive regional real estate database and regional marketing brochures. They have developed a regional trade show team and booth for multiple trade shows each year (ShiftCentral, 2003).

\section{Ontario east summary/background}

The Ontario East Economic Development Commission (OEEDC) was formed in 1988 with 14 members for the purpose of joint marketing and to establish a collective voice for Eastern Ontario regarding issues affecting economic development.

In 2002, Ontario East has 81 members and represents the geographic area from Victoria-Haliburton Counties on the west to the United Counties of Prescott-Russell on the east and bounded by the Ottawa and St. Lawrence Rivers.

Size and scope:

- 200 communities ranging from under 1,000 population to Ottawa.

Structure:

- Governed by a six member board of directors (five government, one private sector);

- One full-time staff person supported by resources from the economic development agencies.

Commission activities:

- Trade Show Participation - members exhibit under the umbrella of 'Ontario East' at several tradeshows throughout Canada and the United States;

- The development of marketing materials;

- Co-operative marketing activities with the Commission's members;

- The maintenance of a regional network of information; 
- An annual fall conference, providing education, updates on legislation and an opportunity to hear high profile speakers on current topics of interest to members;

- Separate workshops and seminars on timely subjects such as ISO 9000 and exporting are also held throughout the year, often in conjunction with provincial ministries;

- Advocacy - the Commission also acts as an advocate for the region with regards to key economic development issues. Over the years Ontario East has presented briefs to both levels of Government on a variety of subjects pertaining to Eastern Ontario.

Examples of the commission's work:

This corridor advertises in many business publications and attends a variety of trade shows. They maintain a regional database and hold an annual conference. They are very much focused on branding Ontario East (see McSweeney chapter in this volume).

\section{Tennessee valley corridor summary/background}

The Tennessee Valley Corridor links southwest Virginia, East Tennessee, and northern Alabama;

The Tennessee Valley Corridor Summit process began in 1995 to strengthen the Valley Corridor's science and technology vision through an annual economic summit series and multiple strategic partnerships;

The Tennessee Valley has historically been one of the poorest and underdeveloped regions in the U.S.;

The Corridor is now one of the fastest growing economies in the U.S.

Size and scope:

- Three states, 400 miles long, with around I40 centres.

Structure:

- 20 member board of directors and a small team of full time staff;

- There were no budget figures available;

- The project is funded by the federal government, economic development agencies, educational institutions and private sector companies.

Targeted industries:

- Science and technology related industries. Examples of the Organization's work.

The annual Summit process has been a driving force behind many projects and initiatives such as:

- the Spallation Neutron Source in Oak Ridge;

- strategic conferencing in Chattanooga;

- the Gateway Pavilion partnership in Knoxville;

- Establishment of a tri-lateral alliance between NASA, DOE and the US Air Force to develop collaborative initiatives in the corridor.

Examples of the organization's work:

The annual Summit process and strategic conferencing has been key to developing this corridor. They have established a tri-lateral alliance between NASA, DOE and the US Airforce (ShiftCentral, 2003).

\section{Hartford-Springfield economic partnership activities summary/background}

- Application for federal aid for regional projects;

- Advocacy of critical transportation and infrastructure initiatives;

- Tourism promotion;

- Support for the region's 26 colleges and outreach to their 108,000 students;

- Attraction of business conventions;

- Business and work force attraction and retention marketing;

- Economic analysis to assess regional strength and weakness;

- Work force development efforts;

- Marketing of the area's rich recreational and cultural assets.

Size and scope:

- 1.6 million people;

- Labour force of more than 780,000;

- 40,000 companies;

- 26 universities and colleges and 110,000 students;

- The corridor is approximately $100 \mathrm{kms}$ long by $60 \mathrm{kms}$ wide.

Structure:

- Managed by a 20 person steering committee made up of private sector, public sector and educational organizations;

- No information on the staffing of the Partnership. 
Targeted industries:

- The Partnership does not target specific industries; however, it has a strong focus on tourism and conventions.

Examples of the partnership's work:

- The creation of marketing materials for the corridor;

- The establishment of 20 sub-committees in areas such as education, tourism development and marketing the region;

- The attraction of several major business conventions to the region;

- Completed a survey of graduating seniors to identify issues and potential actions toward keeping more of the region's 108,000 college students in the region after they graduate;

- Sponsored Career Fairs.

Some results of the corridor project:

The Hartford-Springfield Economic Partnership's Welcome to New England's Knowledge Corridor brochure won the 2002 Literature and Promotions Award of Excellence (general purpose brochure) from the Northeastern Economic Developers Association (NEDA); Established the Massachusetts - Connecticut Cultural Tourism Alliance, an arm of the Hartford-Springfield Economic Partnership (ShiftCentral, 2003).

\section{The Halifax-Moncton growth corridor: An idea in born}

For many decades, the New Brunswick City of Moncton and the Nova Scotia City of Halifax have competed on economic and social levels.

Halifax is the largest city in Nova Scotia and really is the only significant urban centre within the province. It has benefited from an excellent year round port, an international airport and critical mass in terms of population and business representation. Many national companies have their Atlantic headquarters in Halifax.

Moncton is quickly becoming New Brunswick's largest city. It competes with the cities of Saint John and Fredericton for New Brunswick's business investment and for critical mass in terms of population. Its location as the hub of the Maritimes has historically served the city well. It is well established as a transportation and warehousing hub. Moncton benefits from having a bilingual (FrenchEnglish) workforce and relatively good infrastructure.

Both Halifax and Moncton have experienced ups and downs in their economies. Each has been supported historically by relatively few industry sectors. However, over the past decade both cities have successfully transformed their economies. They have significantly diversified their economic fibre and have strong footings in some important emerging sectors such as energy, life sciences, e-learning and a variety of knowledge based industries. Today Moncton and Halifax are growth engines for their respective provinces.

In 2001, the management of the Greater Halifax Partnership and the Enterprise Greater Moncton began having casual meetings designed to share best practices. This quickly grew into a strong working relationship between the two agencies that became conducive to looking at areas of co-operation.

In May of 2002 Stephen Dempsey, President and CEO, of the Greater Halifax Partnership was invited as guest speaker to a Community Breakfast held by the Enterprise Greater Moncton. This is where the concept of an economic corridor between Moncton and Halifax was first floated. A few months later, Ron Gaudet, President and CEO of Enterprise Greater Moncton was invited to Halifax Corporate luncheon. Here Dempsey and Gaudet laid the groundwork to developing the Halifax - Moncton Growth corridor. The business community generally embraced the concept as an idea whose time had arrived. Neville Gilfoy of Atlantic Progress Magazine wrote: " the Halifax - Moncton Growth Corridor creates innovative cultural and commercial activities beyond the cities" (Gilfoy, January 2003).

Once the idea had been floated in Moncton and Halifax a meeting was quickly set up with the Atlantic Canada Opportunities Agency (ACOA) President. During that meeting ACOA agreed to pay for the cost of an Asset Mapping project. This would give the corridor a boundary definition and assist the constituents to better understand the structure and economy of the geographic corridor.

At this stage the concept had understanding and buy in from the Cities of Moncton and Halifax and the Federal Government through ACOA. The next step was to get interest from the stakeholder communities along the corridor.

\section{Engaging stakeholders}

On October 16, 2002 Enterprise Greater Moncton and the Greater Halifax Partnership hosted a meeting in Debert, Nova Scotia with all communities along the corridor. The invited guests included the economic development practitioners and the Mayors and City Managers of each community. Halifax, Moncton and ACOA had gone through a tendering process for the asset-mapping project and we wanted to explain the corridor concept and to introduce the selected company.

The day-long process provided the stakeholder communities with the opportunity to ask questions and to provide significant input into the rational of the corridor and the process for the asset mapping study. The result of the first stakeholders meeting was significant buy in and a commitment to hold a second meeting to include provincial, federal, municipal and business constituents along the corridor. 
On October 28, 2002, the second stakeholder's meeting was held in Sackville, New Brunswick at Mount Allison University. This meeting was similar to the first but allowed for a broader base of understanding and buy in. Provincial, federal, municipal as well as business buy in was imperative for the concept to move forward. This event allowed for a deeper probe into the rationale behind the project. Again the stakeholders overwhelmingly felt that this was an idea whose time had arrived.

Stakeholders left the meeting with an understanding that the corridor would focus on increased economic activity within and between the urban centers and serve as an economic model to address the increasing disparity between urban and rural Atlantic Canada.

\section{The asset mapping project}

The focus of this project, which was contracted to a Moncton-based firm, called ShiftCentral, was to provide a detailed snapshot of the corridor region. It was important for the stakeholders to have a good understanding of the overall composition of the corridor. We needed to understand the people and businesses along the corridor, the infrastructure and the strengths and weaknesses or the impediments to growth. The project was awarded on October 29, 2002, commenced on November 1, 2002 and was to be completed by December 31, 2002. ShiftCentral delivered on budget, on time and provided an exceptional presentation including a Corridor Portal.

\section{Highlights of asset mapping findings}

Economic synergies:

The Halifax-Moncton Economic Growth Corridor has a population base of over 600,000 making it one of the top economic zones in Canada;

- The Corridor has the collective ability to attract skilled labor from both Canadian and international sources;

- The Corridor has the highest percentage of college and university students in North America;

- Collectively, the Corridor has over 110,000 bilingual residents;

- The Corridor offers two international airports, a developed rail infrastructure and a major international port;

- There is some 1.2 million square feet of available office space in the Corridor;

- The majority of New Brunswick and Nova Scotia's tourism assets are located along the Corridor.

Asset summary: Demographics and labour Force

- Solid population growth;

- Solid labour market growth;

- Strong in-migration from other provinces and International locations;

- There is strong migration within the Corridor indicating labour mobility;

- Rural communities around the urban centres benefit from the urban growth;

- The Corridor has a high percentage of professional and technical employment;

- The Corridor is increasing its bilingual population (English/French speaking) at a rate faster than the national average;

- Per capita income derived from government transfers in the Corridor is lower than the national average;

- Still a significant out-migration to certain Canadian locations;

- Part time jobs are on the rise in Halifax;

- The region does not have a 'multilingual' workforce. The percentage of persons speaking languages other than French and English growing at a slower rate than the Canadian average;

- Workforce absenteeism has been rising in recent years;

- The number of EI claimants in on the rise since 1999;

- The labour market is still fairly seasonal in nature;

- Households have less discretionary income than many larger urban centres;

- Households have less liquid assets than many larger urban centres;

- Taxes collected in the Corridor are 12.5 per cent less than the national average.

Asset summary: Labour force infrastructure

- 70 per cent of all New Brunswick and Nova Scotia universities, public and private post-secondary training institutions are located in the Corridor;

- The Corridor has the highest concentration of university students in North America;

- The Corridor has a large contingent of colleges providing a full range of training;

- The education and training sector is embracing e-Learning;

- The Corridor still loses a significant percentage of its graduates to employment outside the region;

- Several of the region's flagship e-Learning companies have gone under in recent months.

Asset summary: Operating cost environment

- Land costs in the major Corridor communities are lower than most communities in North America;

- The cost to build facilities along the Corridor is also lower than most other locations;

- Corridor average hourly wage rates can be up to 48 per cent lower than other Canadian locations and can have an even greater margin compared to U.S. markets;

- From the KPMG Competitive Alternatives report, the total cost of fringe benefits in the Corridor was as much as 20 per cent lower than other Canadian locations, as much as 43 per cent lower than U.S. locations and as much as 80 per cent lower than European locations; 
- Corporate taxes in the Corridor were among the highest of the 80+ locations reviewed in the KPMG Competitive Alternatives report.

Asset summary: Major infrastructure assets

- There are 20 industrial and business parks along the Corridor with over 15,000 acres of space and most have rail services and can support medium to heavy electricity requirements.

- Both the Halifax and Moncton airports have been growing adding cargo facilities and increasing the number of airlines servicing their markets. The Greater Moncton International Airport recently opened its new passenger terminal. The Halifax International Airport has 15 scheduled passenger carriers while the Greater Moncton International Airport has five scheduled passenger carriers. Moncton has added a major new cargo facility and a new cargo facility will be opened in Halifax in 2003.

- $\mathrm{CN}$ rail has major intermodal facilities in Halifax and Moncton and several facilities in between. Facilities include: a CN Steel Transfer - Metals Distribution Facility; a CN CargoFlo - Moncton; CN Automotive Facility Network with locations in both Halifax and Moncton; a CN Forest Products Distribution Facility; a CN CargoFlo in Oxford Junction , Nova Scotia; and a CN Lumber Reload in Truro.

There are at least eight major sectors defined as distinct economic engines:

- Information Technology;

- Industry Training;

- Consulting, Engineering and R\&D Services;

- Film \& Sound Production Activities;

- Marketing/Communications/Public Relations Activities;

- Food Manufacturing;

- Fabricated Metal Products Manufacturing;

- Wood Products Manufacturing.

Life sciences and the energy sector are two emerging sectors.

- The region as a whole spends much less on R\&D than most other provinces;

- 18 of the first round of the Atlantic Innovation Fund projects were awarded to Corridor-based organizations. This represents 60 per cent of the total projects in New Brunswick and Nova Scotia and almost 70 per cent of the total funding;

- The NRC has made major new investments in their R\&D capacity along the Corridor in the past two years including the eLearning Lab at the Universite de Moncton and at their Institute for Marine Biosciences in Halifax;

- There is a significant amount of defense related-R\&D in the Halifax area;

- There are 75 research centres and chairs affiliated with the region's nine universities and degree granting colleges;

- There are six research centres conducting R\&D in the oil and gas area;

- There are three research centres conducting ocean technologies-related research;

- There are six research centres conducting environmental-related research;

- There are eight research centres conducting biotechnology-related research;

- There are a number of R\&D incubators/support organizations.

- Asset Summary: Volume of Commerce

- Nova Scotia and New Brunswick have a strong and balanced interprovincial trade profile with approximately 13 per cent (or $\$ 1$ billion) of the interprovincial trade going each way;

- Imports to New Brunswick and Nova Scotia are up 100 per cent in the past ten years mostly driven by oil and gas products, automobile-related and ship and boat building imports;

- Exports are up 150 per cent over the last ten years with 50 per cent of that increase coming from oil and gas related exports;

- The percentage of Canada's total exports that are transported through Atlantic Canada is down 25 per cent since 1987;

- The percentage of Canada's total imports that are transported through Atlantic Canada is down 47 per cent since 1987;

- Air freight traffic in the Corridor is up in the past few years but air freight traffic in Atlantic Canada overall is down 50 per cent since 1990;

- Cargo activity at the Port of Halifax has been declining in recent years while it is on the increase at the other regional ports;

- CN Rail volumes are down in the past ten years but both the Port and rail volumes are expected to increase in 2002 and beyond. By contrast, cruise ship activity at the Port of Halifax is up strongly in recent years;

- Halifax International Airport departing passenger traffic has been declining since 1999 while Greater Moncton departing passenger traffic is increasing. However, the number of scheduled passenger carriers is increasing at both the Halifax International Airport and the Greater Moncton International Airport;

- Telecommunications traffic is up significantly in the past ten years as a result of the rapid growth in the Corridor's call centre sector.

Asset summary: Utilities capacity

- The Greater Moncton region is being serviced by natural gas. Additional New Brunswick communities such as Sackville are coming online. Nova Scotia communities are on hold;

- The Corridor is served by two local service telecommunications providers: Aliant and EastLink;

- All of the major communities along the Corridor are served by broadband infrastructure;

- All of the major communities along the Corridor could service small to medium-sized call centre requirements as well as telework programs, etc. Some of the peripheral communities still require broadband access. Rogers and Eastlink provide some of the Corridor's communities with residential broadband services; 
- The Corridor is served by several long distance providers including: Aliant, Eastlink, Sprint, AT\&T Canada and Primus Canada;

- The Corridor is served by four wireless telecom providers including: Aliant, Rogers AT\&T, Microcell and Telus;

- Many of the industrial parks along the Corridor can accommodate heavy energy users.

Advocacy in support of a growth corridor

We entered 2003 with wide based stakeholder support of the concept of a Halifax - Moncton Growth corridor; with a strong understanding of the assets along the corridor and with a sense of optimism that we were moving towards something of significance. This was the time to solidify political and bureaucratic support for this initiative. In March a meeting was held again in Sackville, New Brunswick, to access where we were and to develop a plan for the next steps.

The next steps include a strategy to:

- Develop a high level Advisory Council made up of key business leaders along the corridor;

- Arrange for high level meetings with key federal ministers and key federal department heads;

- Make a request for federal dollars to develop a solid business plan for the corridor;

- We were encouraged by the fact that the media had developed a keen sense of interest in the corridor concept and we were going to leverage this attention.

\section{Media - Managing the expectations}

Almost since the Corridor Concept was first introduced in Moncton in May of 2001 the media have been keenly interested in telling the story. The story of the development of the corridor has been partly told by such publications as Atlantic Progress Magazine, (January 2003); Fredericton Daily Gleaner, (September 19,2002); the Chronicle Herald, (January 31, 2003); the EDAC Communique; The Daily News, (September 20, 2002); the Moncton Times and Transcript, (September 19, 2002); Canadian Business Magazine, (October 14, 2002); the Globe and Mail (September 20, 2002, April, 2003) and most recently the CBC, (Mainstreet Program - Aired September 20, 2002). In fact, the CBC is presently working on a 48 minute documentary under a new summer programming entitled 'The House'.

This attention comes with both benefits and costs. On the benefit side, we have found it very easy to engage the federal government in discussion around the corridor issue because they have a general knowledge of the concept due to briefings from their staff primarily stemming from media coverage. On the negative side, the hype does put a lot of pressure on us to perform at a very quick rate and it does allow for the possibility of developing unrealistic expectations.

On June $5^{\text {th }}$ and $6^{\text {th }}, 2002$, Gaudet and Dempsey visited Ottawa to meet with several high level Federal Department officials on the corridor concept. The media attention had clearly paved the way for an understanding of the concept and contributed to a high level of interest on the part of the Federal Government. The intent is to retain the media's interest in this initiative while trying to manage stakeholder expectations.

\section{Going forward}

The next several months will be crucial for the development of the Halifax - Moncton Growth Corridor. We are moving into the development of an implementation and action plan. To that end, the stakeholders met in Halifax on June $12^{\text {th }}, 2003$ to bring all stakeholders up to date on the corridor and to explain the next steps. We asked the federal government for a small amount of assistance to develop the action plan.

As the action plan is developed we will be putting an advisory forum of high-level business people together to assist with the vision, future direction and the branding of the corridor.

Halifax-Moncton growth corridor overview

Phase 1: Asset mapping

- This exercise was to determine the economic assets along the Corridor and identify some of the key advantages and strengths. It also involved:

- Stakeholder Briefings;

- Public announcement;

- Follow up.

Phase 2: Strategic Plan

- This phase will include defining what the Corridor should do to support the objective of significant economic growth in the Corridor. This will include:

- Business and marketing plan;

- Tools/collateral development;

- Visual identity;

- Stakeholder relations;

- Secure funding. 
Phase 3: Implementation

- This will involve rolling out the plan identified in Phase 2. Key elements to include:

- National initiative - pilot project for regional economic growth;

- Objective - Fastest growing region;

- Complementary to existing activity;

- Policy/marketing.

Common themes among regional growth economies

There was strong local/regional leadership and vision with the government and private sector. This was typically stimulated after the region realized the fundamental need for change. This pervasive realization that change was necessary allowed governments, unions and other stakeholder groups to get buy-in from their constituencies to make these needed changes. There were substantial proactive initiatives to stimulate growth (incentives/tax cuts, infrastructure development, union concessions, labour market initiatives, etc.)

There was significant federal and/or state/provincial government support of local initiatives (state level in the Southern US, state/federal in Curitiba, Brazil, federal/EU in Ireland). Foreign direct investment is critical to growth economies (400 per cent increase in Ireland over ten years, 500 new companies in Curitiba, Brazil over 15 years, several southern U.S. states led all of the USA for FDI through the 1990s) (ShiftCentral, 2003, 103).

\section{The vision: A national pilot project for regional economic growth}

The stakeholders have a vision for the Halifax-Moncton Growth Corridor as a pilot project for regional and inter-provincial foreign direct investment attraction. The critical mass of over 600,000 people combined with the strong social, economic and infrastructure links makes the Halifax-Moncton Growth Corridor an excellent location to pilot this model. If successful, it could be replicated across Canada in regions with economies that are lagging behind such as Sudbury/North Bay, Ontario and other areas within Atlantic Canada.

Guiding principles of the corridor:

- This is a national pilot project. The intent is to build an economic development model that leverages in-Corridor, provincial and federal government economic development infrastructure for the growth of both Nova Scotia and New Brunswick.

- The Corridor will be among the fastest growth regions in North America;

- The Corridor will stem the chronic problem of out-migration from Atlantic Canada. The region's youth should have the option to stay or go;

- There is and will continue to be strong private sector leadership for the initiative;

- FDI will be a prime driver of the Corridor's growth;

- The quality of jobs created in the Corridor will be elevated;

- The Corridor initiative will involve in-region growth activities as well as externally focused investment attraction. There is a strong linkage between FDI and local business growth - buyer/supplier networks and support services;

- The Corridor initiative will involve immigration promotion activities;

- The Corridor initiative will support both rural and urban growth with strategies targeted at the +/- 200,000 people living in rural and sub-urban communities.

\section{Lessons learned}

Similar to any new initiative, particularly an economic development initiative there are lessons learned in the development stages. These lessons are that the champions of the project must engage all stakeholders, identify the regional benefits and deal with opposing interests.

Engage stakeholders

It should be remembered that initially not all stakeholder communities would see a corridor concept as something positive for their municipality. There may be doubt, fear or even mistrust as to the rational. There may be fear from the smaller communities that their interests will be lost to the clout of the larger municipalities. There may be concern from economic development personnel that their jobs could be in jeopardy.

It is very important to bring the stakeholders together as often as possible in the development process. Their concerns must be heard, understood and addressed. It is also important to receive their input into the direction and structure of the corridor. This is timeconsuming but is essential to the successful rollout of the concept.

\section{Identify Regional Benefits}

It is important to position the corridor as a positive move forward for the region. It details the benefits of critical mass, infrastructure, labor force, marketing and advocacy. It points to the benefits of cooperation versus competition. It addresses the positive aspects of the region and identifies it as a regional unit of cooperation with a shared set of priorities and objectives. 


\section{Deal With Opposing Interests}

Regardless of how well the concept is explained or rolled out there will be some within the region that are opposed to the idea. This can stem from a political, economic or social standpoint. It is important to identify these people or organizations and to be aware of their rational behind their objections. You may not be able to bring them around but attempt to include them in your planning. Often they just want their objections heard.

While it is important to recognize the objections it is not advisable to spend an inordinate amount of time trying to win the opposing interest over. It simply takes too much time and will take away from the momentum being developed.

\section{Policy in support of Canadian growth corridors}

It would serve Canada well if we had a federal policy to support growth corridors within the country. While there probably exists some programs within various departments that could be used to facilitate specific corridor activities there is not a source point where regions can go to receive assistance with corridor structure, governance, and activity support. A policy that addressed growth corridor development would encourage regions to work more collaboratively and would assist the government address the urban - rural dilemma.

Policy should encourage a national network of growth corridors with the intent of sharing best practices and joint initiatives such as international trade shows. Encouragement of growth corridors tying the urban centres to the rural areas could prove to be a policy whose time has come. If done thoughtfully, Canada, could be a model for the world in terms of economic development and social policy.

\section{Author Biography}

Ron Gaudet holds a Bachelor of Arts degree (Economics), as well as a Bachelor of Education. In 1984, he was employed with the Saint John Fundy Commission as Economic Development Officer. He held this position until 1987, when he was hired as Business Analyst by the YM-YWCA Enterprise Centre in Saint John. In 1990, Ron was appointed to the position of Manager, Business Development for the Centre. In January of 1991, Ron was employed by the Greater Moncton Economic Commission (now known as Enterprise Greater Moncton) as Director, Business Development; he was then elected President and Chief Executive Officer in 1994. Enterprise Greater Moncton is the coordinating body with respect to economic development efforts in the region. Its primary focus is on business development, entrepreneurship, investment attraction, marketing and strategic planning.

Notable achievements in his career include:

- Being honoured on a national basis by receiving the Economic Developers Association of Canada`s most prestigious "Economic Developer of the Year" Award in 1998; and

- In the Spring of 1999, Ron was among Canada`s Top 40 Under 40. This national awards program is designed "to celebrate extraordinary and inspiring achievements by a new generation of business leaders who will drive Canada into the next millenium".

- In 2000, Ron was named one of Atlantic Canada`s “Top 50 CEO’s” by Atlantic Business Magazine.

\section{References}

Atlantic Business, Volume 13, Number 6, 2002.

Atlantic Business, Volume 14, Number 2, 2003.

Atlantic Progress, June/July 2002.

Business Voice, October 2002.

Business Voice, January 3, 2003

Canadian Business, October 14, 2002.

CBH / Halifax, Main Street, September 20, 2002.

Chronicle Herald, September 19, 2002.

Chronicle Herald, September 20, 2002.

Chronicle Herald, October 29, 2002.

Chronicle Herald, January 31, 2003.

Fredericton Daily Gleaner, September 19, 2002. 
Investment Executive, January 29, 2003.

L'Acadie-Nouvelle, September 19, 2002.

McSweeney, Eric, Increasing the Policy Impact and Influence of the OntarioEast Economic Development Commission, Draft paper, June 2003.

Moncton Times-Transcript, September 19, 2002.

NB Telegraph-Journal, September 19, 2002.

NB Telegraph-Journal, November 6, 2002.

Progress, January 2003.

ShiftCentral, Setting the Context for a Halifax-Moncton Growth Corridor: A Review of Five Leading Economic Corridors, Oct. 2002 .

ShiftCentral, Halifax - Moncton Growth Corridor, Selected Research Highlights, Prepared for Enterprise Greater Moncton; Jan. 13, 2003.

ShiftCentral, Halifax - Moncton Growth Corridor Asset Mapping - Baseline Research Project, Prepared for The Greater Halifax Partnership, Enterprise Greater Moncton, and the Atlantic Canada Opportunities Agency, Jan. 2003.

ShiftCentral, Halifax - Moncton Growth Corridor, Final Report Submission to the Atlantic Canada Opportunities Agency, April 30, 2003.

The Daily News, September 20, 2002.

The Globe and Mail, September 20, 2002.

The Globe and Mail, April 2003.

Times \& Transcript, November 1, 2002.

Truro Daily News, September 20, 2002.

Truro Daily News, January 29, 2003.

Truro Daily News, March 24, 2003.

Truro Daily News, March 26, 2003.

Williams, B., "Urban Development Policies in the Dublin Region", Reacting to Rapid Economic Development RICS Cutting Edge Conference, Oxford Brookes University, Sept. 2001.

Zavergiu, R. M., Silicone Valley: Transportation Advancements and the Interactive Megalopolis, November $27,1998$. 